\title{
Role of telemedicine and its implementation in Nepal
}

\section{Journal of GANDAKI MEDICAL COLLEGE- NEPAL (J-GMC-N)}

\section{J-GMC-N | Volume 14| Issue 02| Jul-Dec 2021}

Correspondence:

Dr Krishna Subedi

Department of Community Dentistry, Gandaki Medical College Teaching Hospital, Pokhara Nepal Email: drkrishnasubedimdsphd@ gmail.com

DOI: $10.3126 /$ jgmcn.v14i2.41221

\author{
Krishna Subedi ${ }^{1}$, Nuwadatta Subedi ${ }^{2}$ \\ 'Department of Community Dentistry, ²Department of Forensic Medicine, \\ Gandaki Medical College Teaching Hospital, Pokhara Nepal
}

There are several challenges of impartial and cost-effective provisions of health care services globally. This is particularly more prevalent in the developing countries where there are numerous factors hampering the availability of even the basic health care facilities to all the people. The geographical challenges, difficulty in access and unavailability of other basic resources affect the provision of proper health care services to the people living in rural and remote areas. Telemedicine has been one of the smart solutions to overcome such issues. ${ }^{1}$

Though the usefulness of telemedicine has amplified just during the Corona Virus Disease 2019 (COVID-19 pandemic), it has a long history and has been introduced well before a century. The term telemedicine had been coined in the 1970s, which literally meant "healing at a distance". ${ }^{2}$ World Health Organization has adopted the definition of telemedicine as "the delivery of health care services, where distance is a critical factor, by all health care professionals using information and communication technologies for the exchange of valid information for diagnosis, treatment and prevention of disease and injuries, research and evaluation, and for the continuing education of health care providers, all in the interests of advancing the health of individuals and their communities". ${ }^{3}$

Telemedicine is not a separate medical specialty; on the contrary, it is considered as a tool which is used by healthcare providers to propagate the traditional medical practice beyond the boundary of a typical medical practice. It comprises of asynchronous (store and forward), synchronous (real time consultation), remote monitoring, and mobile health care service (mHealth) technologies. Telemedicine applications and services include email, two-way video, wireless tools, smart phones, and other communication technology tools. ${ }^{4}$ The scope of telemedicine has been broadened due to rapid development in information and communications technologies.

The main rationale for the development of telemedicine services is the possibility to provide health services to persons whose access to health care is restricted for one or another reason. ${ }^{5} \mathrm{Nepal}$, like many low- and middle-income countries, faces common issues such as: limited access to healthcare (due to geographic remoteness and poor or no public transportation), chronic shortage of healthcare professionals, poverty and illiteracy coupled with the high cost of private healthcare services, poor quality of care services at public sector hospitals and institutions, sparse population, adverse seasonal weather and road conditions, lack of health insurance and a less mobile aging population. ${ }^{6}$ Telemedicine in some instance helps to break out the barriers to access the health in rural areas. Sir Arthur C. Clarke says that "any sufficiently advanced technology is equivalent to magic". As telemedicine seems to be 
magic by making the world so small connecting the health professionals all around the world. ${ }^{7}$

The constitution of Nepal 2072 BS (2015 AD) established health as a fundamental right of people. Therefore it is the responsibility of the nation to provide health care services to all including control of communicable diseases, reduce infant and maternal mortality rate to the desired level, control the ever increasing prevalence of non-communicable diseases and timely management of unpredictable health disasters, and provide quality health services to senior citizens, physically and mentally impaired people, single women especially to the poor, marginalized and vulnerable communities. ${ }^{8}$ One of the barriers to accelerate universal health coverage by Nepal is disparity in rural and urban areas. Lack of health care workers in rural areas is a universal problem which affects both developing countries and developed countries equally. ${ }^{9}$ To overcome this hurdle and achieve universal health coverage, effective use of telemedicine in Nepal is inevitable. Telemedicine has been realized by many countries as major tool to deliver decent and improved medical services with equality. It is therefore included in national healthcare strategies outlined by several nations. ${ }^{10}$

Nepal started its digital journey in the health sector with the launch of integrated Health Management and Information System (HMIS) in 1993. Since then, the nation has undertaken several initiatives and one of them is the introduction of telemedicine system. ${ }^{6}$ Telemedicine was introduced in Nepal in 1998 in order to reduce casualties from mountain climbing by monitoring vital signs at the Everest base camp through satellite connection with Yale University. It validated the ability of tele-medicine to connect a team in a remote and severe environment with a medical center to provide advanced care effectively. ${ }^{11}$ National Health Education, Information and Communication Centre (NHEICC) has developed national health communication policy 2012, which emphasizes use of electronic means and media for health education, information and communication. ${ }^{12}$ National health policy of Nepal in 2076 BS (2019 AD) had put telemedicine in strategic plan for its development, expansion and regulation. ${ }^{13}$ With the rise of COVID-19 pandemic, Nepal Medical Council (NMC) has also prepared telemedicine guidelines for registered medical practitioners in Nepal in 2020 A.D. $^{14}$ Medical practitioner with a valid license of $\mathrm{NMC}$ is entitled to provide telemedicine consultation to patient from any part of Nepal. NMC recommends that the fees for tele-services shall not exceed that of comparable in-person care. ${ }^{14}$

In the present time, online consultation is provided by various organizations and applications in Nepal. Health services consultations for various specialties including psychiatry, ENT, dermatology, cardiology, ophthalmology, pediatrics, pulmonology, urology, dentistry, cancer care, viral and infectious diseases, women's health and pregnancy, gastroenterology, anesthesiology, general physician, Ayurveda etc. are available. There are provisions of online live video consultation by specialized doctors also.

With the COVID-19 pandemic the usefulness of telemedicine and the ability to provide safe, rapid, and high-quality care has become more evident worldwide. This is a major shift in advancing the current and the future of telemedicine caused by the current pandemic that has changed the world like no war or catastrophe since the 1918 Spanish flu. For the benefit of health of people in real scenario, telemedicine must be fully integrated telepresence, and should be used instead of in-person hospital visits not only during the pandemic but also in daily use as much as possible. In addition, the entire perioperative care process can be done virtually; when there is really little or no benefit to a physical visit, particularly during health crisis, public health emergencies and disasters, which highlights the need for further application and integration of telemedicine. ${ }^{15}$ There are various legal and ethical issues which may arise while using telemedicine such as: licensure, confidentiality, accountability, jurisdiction, liability, privacy, consent, and malpractice. ${ }^{16}$ The NMC recommends to use telemedicine limiting medical teleeducation only among medical practitioners concerning privacy, safety, quality and ethical issues. Consultation should take place only in the presence of local registered medical practitioner in Nepal with the ethical and legal liabilities to be borne by medical practitioner. ${ }^{14}$

In conclusion, no one can question the usefulness of telemedicine in health sector in the present context, but certain issues like legal, ethical, broadband access and infrastructure development should be addressed to improve the healthcare access and outcomes for its proper implementation in Nepal.

\section{REFERENCES}

1. Greenhalgh T, Procter R, Wherton J, Sugarhood P, Shaw $\mathrm{S}$. The organising vision for telehealth and telecare: discourse analysis. BMJ Open. 2012;2(4):e001574. 
DOI: $\quad$ 10.1136/bmjopen-2012-001574

PMID: 22815469.

2. Strehle EM, Shabde N. One hundred years of telemedicine: does this new technology have a place in paediatrics? Archives of disease in childhood. 2006;91(12):956-9. DOI: 10.1136/adc.2006.099622 PMID: 17119071.

3. Sood S, Mbarika V, Jugoo S, Dookhy R, Doarn CR, Prakash $\mathrm{N}$, et al. What is telemedicine? A collection of 104 peerreviewed perspectives and theoretical underpinnings. Telemedicine and e-Health. 2007;13(5):573-90. DOI: 10.1089/tmj.2006.0073 PMID: 17999619.

4. Aziz HA, Abochar H. Focus: Health informatics. Clin Lab Sci. 2015;28(4):256-9. DOI: 10.29074/ascls.28.4.256

5. Grigsby J, Kaehny MM, Sandberg EJ, Schlenker RE, Shaughnessy PW. Effects and effectiveness of telemedicine. Health Care Financing Review. 1995;17(1):115. 10.1089/tmj.1.1995.1.31 PMID: 10165320.

6. 2019 digital Nepal framework unlocking Nepal's growth potential. Government of Nepal ministry of communication and information technology. Available from: https://mocit.gov.np/application/resources/ admin/uploads/source/EConsultation/EN\%20 Digital\%20 Nepal\%2 0 Framework\%2 0V8.4\%20 $15 \% 20 J u l y \% 20 \% 202019$.pdf. [Accessed on $29^{\text {th }}$ November 2021].

7. World Health Organization. Telemedicine: opportunities and developments in member states. Report on the second global survey on eHealth. World Health Organization; 2010. Available from: https://www.who.int/goe/publications/goe_ telemedicine_2010.pdf. [Accessed on $29^{\text {th }}$ November 2021]

8. Annual report, Department of health services 2073/2074 (2016/17). Government of Nepal Ministry of Health and Population. Available from: https:// dohs.gov.np/wp-content/uploads/2018/04/Annual_ Report_2073-74.pdf. [Accessed 29 ${ }^{\text {th }}$ November 2021].
9. Ailuogwemhe J, Rajbhandari R, Iliaki E, Villar M, Dieterich M. Tackling shortages of health care workers in rural Nepal:"Train to Retain". Harvard School of Public Health, Student Project, ID. 2005;262. Available from: http://nsi.edu.np/images/category/Tackling_ Shortages_of_Health_Care_Workers_in_Rural_Nepal_ Train_to_Retain.pdf. [Accessed on 29 ${ }^{\text {th }}$ November 2021]

10. Khemapech I, Sansrimahachai W, Toachoodee M. Telemedicine-meaning, challenges and opportunities. Siriraj Medical Journal. 2019;71(3):246-52. DOI: 10.33192/Smj.2019.38

11. Angood PB, Satava R, Doarn C, Merrell R. Telemedicine at the top of the world: the 1998 and 1999 Everest extreme expeditions. Telemedicine Journal and e-Health. 2000;6(3):315-25. DOI: 10.1089/153056200750040174 PMID: 11110635.

12. National e-Health Strategy 2017. Ministry of Health Government of Nepal. Available from: https://www. mohp.gov.np/attachments/article/368/Nepal_e_ health_strategy_Eng.pdf. [Accessed on $29^{\text {th }}$ November 2021]

13. National health policy 2019. Available from: https:// drive.google.com/file/d/1K2fAzRhEYLfYIMs52hDR IwRYvGf03C92/view. [Accessed on $29^{\text {th }}$ November 2021].

14. Telemedicine Guidelines for Registered Medical Practitioners in Nepal. Available from: https://nmc. org.np/files / $4 /$ Telemedicine $\% 20$ guidelines $\% 20$ for $\% 20$ registered $\% 20$ medical $\% 20$ practitioners $\% 20$ in\%20nepal.pdf. [Accessed on $29^{\text {th }}$ November 2021].

15. Latifi R, Doarn CR. Perspective on COVID-19: finally, telemedicine at center stage. Telemedicine and e-Health. 2020 Sep 1;26(9):1106-9. DOI: 10.1089/ tmj.2020.0132 PMID: 32408804.

16. Stanberry B. Legal and ethical aspects of telemedicine. Journal of telemedicine and telecare. 2006 Jun 1;12(4):166-75.DOI: 10.1258/135763306777488825 PMID: 16774696. 